\title{
Decadal Variation in Surface Characteristics over Xinjiang, Western China, from T/P Altimetry Backscatter Coefficients: Evidence of Climate Change
}

\author{
Jinyun Guo ${ }^{1,2, *}$, Lei Yang ${ }^{1}$, Xin Liu $^{1}$, Xiaotao Chang ${ }^{2,3}$, and Cheinway Hwang ${ }^{4}$ \\ ${ }^{1}$ College of Geodesy and Geomatics, Shandong University of Science and Technology, Qingdao, China \\ ${ }^{2}$ Key Laboratory of Surveying and Mapping on Island and Reef of NASMG, Qingdao, China \\ ${ }^{3}$ Satellite Surveying and Mapping Application Center of NASMG, Beijing, China \\ ${ }^{4}$ Department of Civil Engineering, National Chiao Tung University, Hsinchu, Taiwan
}

Received 12 April 2012, accepted 1 November 2012

\begin{abstract}
The backscatter coefficient, known as sigma0, is an important measurement of satellite radar altimetry and a key parameter for land altimetry because of its close relationship with the physical properties and geometric features of land coverage under global/regional climate change effects. Using the TOPEX/Poseidon GDR-M dataset from January 1993 to December 2004, we study the spatial and temporal distribution of sigma0 at bands $\mathrm{Ku}$ and $\mathrm{C}$ over Xinjiang, western China. The results show that the sigma0 is influenced by the water distribution over land and the time evolution of sigma0 has clear seasonal changes. River basins or deserts are classified over the spatial distribution based on different sigma0 values. For example, high sigma0 values are found in the Tarim River Basin and low values are found in the Taklimakan Desert. The periodic components of sigma 0 time series are determined using the fast Fourier transformation method. The annual variation is the dominating cycle and the semi-annual variation is the secondary signal. The amplitudes of sigma0 time series at bands Ku and $\mathrm{C}$ are also given and most areas have quite low amplitudes except for the Tarim River Basin. Several areas including the Tarim River Basin, Tianshan Mountain and Taklimakan Desert are selected for sigma0 time series spacial analysis to discuss the reasons for variations in sigma0. The main factors are precipitation and vegetation growth, which are affected by the global/ regional climate change. The correlation between the brightness temperature, which is related to the water-vapor content in the atmosphere measured by TMR at the $21 \mathrm{GHz}$ channel and sigma 0 at two bands, is analyzed.
\end{abstract}

Key words: Xinjiang, Satellite radar altimetry, Backscatter coefficient, Geographical condition monitoring, TOPEX/Poseidon

Citation: Guo, J., L. Yang, X. Liu, X. Chang, and C. Hwang, 2013: Decadal variation in surface characteristics over Xinjiang, western China, from T/P altimetry backscatter coefficients: Evidence of climate change. Terr. Atmos. Ocean. Sci., 24, 565-579, doi: 10.3319/TAO.2012.11.01.01(TibXS)

\section{INTRODUCTION}

The satellite radar altimeter was designed primarily for oceanographic science to measure the sea surface topography and sea wave height. With more than 30 years development, great achievements have been made in the ocean altimetry technique (Rapley 1990; Chelton et al. 2001). Satellite radar altimetry applications are not only for open oceans where deep researches have been performed, but also for coastal seas with much more complex conditions (Freeman and Berry 2006; Hwang et al. 2006; Guo et al. 2010) as well as monitoring water level variations in inland lakes (Campos et al. 2001; Hwang et al. 2005; Guo et al.
2009, 2011; Lee et al. 2011). Over coastal seas the waveform retracking technique is used to improve altimetric data to study geodesy, geophysics and oceanography (Guo et al. 2006, 2010; Hwang et al. 2006; Chang et al. 2008). Radar altimetry applications over lands mainly utilized the height data and it is difficult to obtain the precise measurement of land elevation because of the complexity of the land surface and the large radar pulse footprint. The backscatter coefficient, known as sigma0 (Seeber 2003), is one key parameter for radar altimetry land applications (Guzkowska et al. 1988; Berry 2000; Papa et al. 2003; Bramer et al. 2004; Chu et al. 2009).

\footnotetext{
* Corresponding author

E-mail: jinyunguo1@126.com
} 
The backscatter coefficient is associated with the surface roughness and physical characteristics (Skolnik 1990), and can be used to build a wave-wind model over open oceans to calculate the sea wave height and sea wind velocity (Brown et al. 1981; Chelton and Mccabe 1985). On land, due to the diversity of land coverage characteristics (including the soil moisture, vegetation, snow, water, ice et al.), and the complex fluctuation of topography (slope and terrain), the backscatter coefficients contain useful but complex land surface feature information. From the spatial distribution of sigma0, large-scale land types still can be clearly identified, e.g., mountains, river basins, gobis and deserts (Guo et al. 1997, 2012; Papa et al. 2003; Bramer et al. 2004). The backscatter coefficients can also be used to analyze the variations in land surface features caused by seasonal variation and climate change from the long time span of altimeter data, which is meaningful for research on global/regional climate and environment changes. Early works on backscatter coefficient land applications were limited by the short data time span and focused mainly on deserts, prairies or rainforests, e.g., the Simpson Desert (Ridley et al. 1996), the Taklamakan Desert (Bramer et al. 2004), the African Savanna (Papa et al. 2003) and the Amazon Selva (Campos et al. 2001).

The study area is Xinjiang in western China, located over $35-50^{\circ} \mathrm{N}$ and $73-97^{\circ} \mathrm{E}$. Xinjiang is in the center of Eurasia and is divided into a southern part covering the Tarim Basin between the Tianshan Mountain and the Kunlun Mountain and a northern part covering the Junggar Basin between the Tianshan and Altai mountains. The Tarim River is the longest inland river of China, known as the mother river of Xinjiang flowing through the Taklamakan Desert. The second largest desert in Xinjiang is the Gurbantunggut Desert, which is in the central part of the Junggar Basin. Over the Tianshan, Kunlun and Karakorum mountains, there are a number of glaciers with permanent snow cover. In terms of land coverage diversity, Xinjiang is one of the best places to test the backscatter coefficient land application for satellite altimetry.

The backscatter coefficients at bands $\mathrm{Ku}$ and $\mathrm{C}$ of TOPEX/Poseidon (T/P) from January 1993 to December 2004 over Xinjiang, China, will be analyzed in terms of spatial and temporal distributions under climate change effect. The backscatter coefficient distribution at two bands and their differences will be presented to analyze its relationship with land surface types and the different responses of land to radar pulses at different frequencies. We will analyze the backscatter coefficient time series for 12 years over the Tarim River Basin, the Taklamakan Desert and Tianshan Mountain to understand the major variation components. The relationship between the brightness temperature measured by TOPEX Microwave Radiometer (TMR) and sigma0 will also be analyzed.

\section{BACKSCATTER COEFFICIENTS AND DATA PROCESSING}

The backscatter coefficients were extracted from the T/P GDR-M (Merged Geophysical Data Record) dataset released by AVISO/Altimetry (Active Archive Data Center for multi-satellite altimeter missions). The TOPEX altimeter operates at band $\mathrm{Ku}(13.6 \mathrm{GHz})$ and band $\mathrm{C}(5.3 \mathrm{GHz})$, and the Poseidon-1 altimeter operates at a single Ku frequency. The GDR-M data were generated from measurements of the two altimeters to reinforce unity of the T/P mission and contained fully homogeneous backscatter coefficients (sigma0). Sigma0 depends on the reflected radar pulse power and can be calculated from the radar waveforms echoed from the reflecting surface (Fu and Cazenave 2001; Guo et al. 2012). The simplified sigma0 equation for the radar altimeter is

$\sigma_{0}=\frac{P_{r} 64 \pi^{2}\left(1+h / R_{e}\right)}{P_{t} G^{2} \lambda^{2} c \tau} h^{3} L_{a t t} L_{a t m} L_{T}$

where $G$ is the bore sight antenna gain, $P_{r}$ the received power, $h$ the satellite orbit altitude, $R_{e}$ the earth radius, $P_{t}$ the transmitted power of antenna edge, $\lambda$ the radar wavelength, $c$ the speed of light, $\tau$ the pulse width, $L_{a t t}$ the altitude angle attenuation, $L_{a t m}$ the atmospheric attenuation, and $L_{T}$ the attenuation related with temperature.

On September 15, 2002, T/P satellite assumed a new orbit midway between its original ground tracks. Thus, we used T/P data from January 1993 to December 2004 and the overlapping period $(2002$ - 2004) to improve the spatial resolution of sigma0. Figure 1 shows the mean monthly sigma0 over Xinjiang and the original and shifted ground tracks of T/P from January 1993 and December 2004. The mean monthly sigma0 values were calculated using sigma0 derived from each GDR-M pass file after data smoothing to remove abnormal vacations. Sigma0 values on $5^{\prime} \times 5^{\prime}$ grids were achieved using the gridding algorithm used in the adjustable tension continuous curvature surface (Smith and Wessel 1990). The data for these grids were then analyzed with the fast Fourier transformation (FFT) and the least squares spectral analysis methods (Guo et al. 2012) to determine various temporal change components at each of the grid points.

\section{SPATIAL DISTRIBUTIONS}

Using the interpolation method provided by the GMT software (http://gmt.soest.hawaii.edu/), the T/P sigma0 spacial distributions at bands $\mathrm{Ku}$ and $\mathrm{C}$ as well as the absolute difference values and the relative difference over Xinjiang are shown in Fig. 2. Due to scattering characteristic variations for different land types, high sigma0 values are always present at flat and wetland areas while low sigma0 values occur over the mountainous and dry areas. 
As shown in Figs. 2a and b, oases in the Tarim River Basin can be obviously distinguished as the high values where the backscattering capacity is strong because of large soil moisture, good vegetation coverage and high dielectric constant. In addition, the presence of a water surface over the Tarim River Basin also affects sigma0. A river with the enough width may act as the leading factor for high sigma0 value (Papa et al. 2003). Another evident area with high sigma0 values is in the Junggar Basin which forms a sub-triangle in northern Xinjiang. Although the Junggar Basin contains the Gurbantunggut Desert, the second largest desert in China, the climate here is much moister than the Taklamakan Desert in the Tarim Basin. Some plants can live in dozens of kilometers in the deep Gurbantunggut Desert because of the influence of airflow from the Arctic Ocean. Thus, large differences exist in the dielectric properties between the Gurbantunggut Desert and the Taklamakan Desert. In general, the sigma0 values are higher in northern Xinjiang than the southern part. Comparing band $\mathrm{Ku}$ and band $\mathrm{C}$ shows more evident features over the Tianshan and Kunlun mountains, shown in Fig. 2. One reason is that the microwave length of band $\mathrm{C}$ is larger than that of band $\mathrm{Ku}$, making it less sensitive to small-scale surface roughness and relatively easy to detect large-scale surface features.

Figures $2 \mathrm{c}$ and $\mathrm{d}$ show the absolute and relative differences in sigma0 between bands $\mathrm{C}$ and $\mathrm{Ku}$ respectively. Values for band $\mathrm{C}$ are generally larger than those for band $\mathrm{Ku}$. Figure 2c shows the largest difference values are situ- ated at the Shunha Gobi in the northeastern Xinjiang, which presents the Yadan landform and has little precipitation. Because of the different penetration depths of two-frequency radar pulses over the arid area (Papa et al. 2003), the backscatter coefficients also show a significant variation. Therefore, areas that yield high difference values generally are arid or semi-arid places, such as the downstream Tarim River Basin located in the northeast Tarim Basin and linked to the Shunha Gobi. The absolute difference values over the Taklamakan Desert are not as significant as the Shunha Gobi but the relative difference values are similar to the Shunha Gobi. The reason is that sigma0 values at bands $\mathrm{Ku}$ and $\mathrm{C}$ are relatively smaller but the statistics prove that sigma0 values at band $\mathrm{C}$ are nearly two times those at band $\mathrm{Ku}$. On the other hand, over the main part of the Tarim River Basin, although the absolute difference is large, the relative difference shows very small values, which is associated with the wide distribution of oases along the river.

\section{TEMPORAL DISTRIBUTIONS}

Considering the close relationship between sigma0 and the land coverage, the sigma0 should change if land surface variations happened. If the variations were of obviously seasonal characteristics, such as the growth of vegetation and precipitation, the sigma 0 would change in the seasonal period sequentially. If there are some anomalous climate phenomenon, like flood, drought and snow disaster, which can

\section{Ground track of T/P over XinJiang}

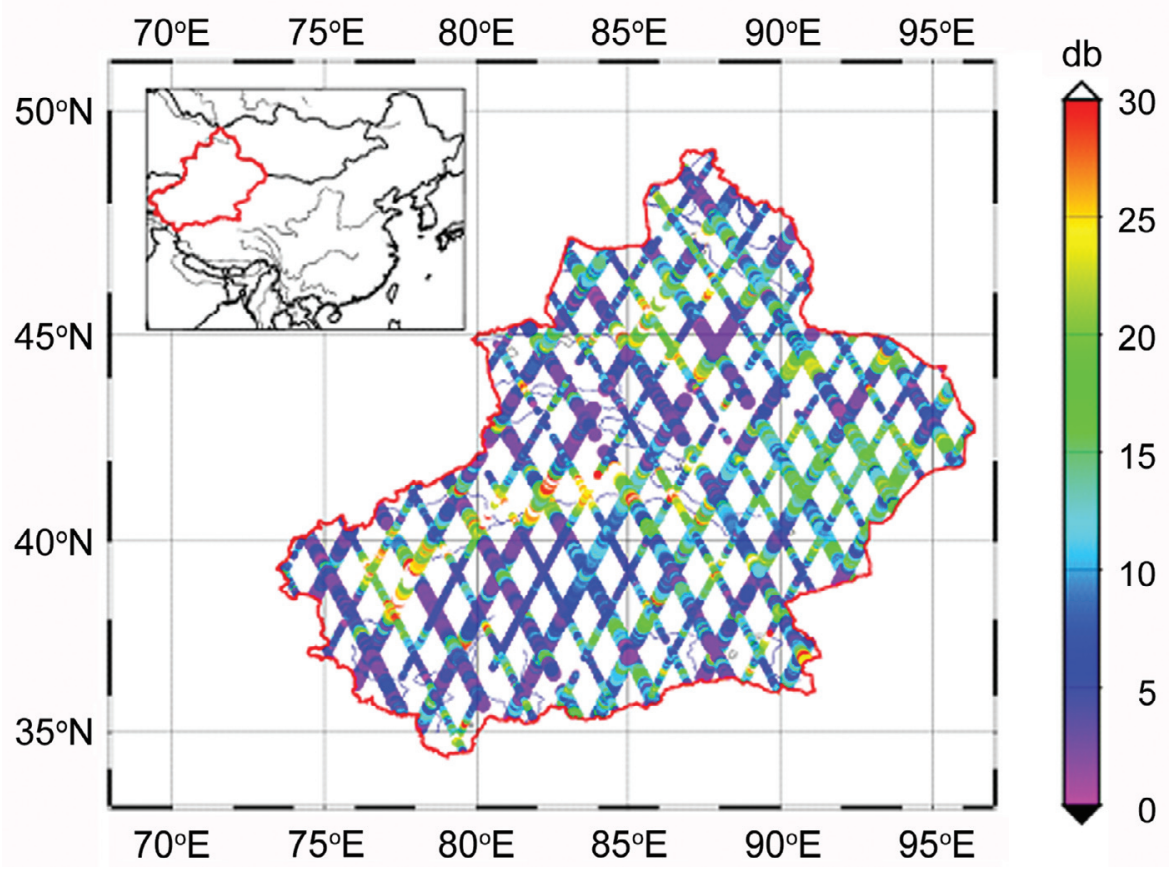

Fig. 1. Mean backscatter coefficients over Xinjiang along T/P ground tracks. The original ground tracks are in thick lines and the shifted tracks are in thin lines. 
(a) Spatial distribution of sigma0 at Ku

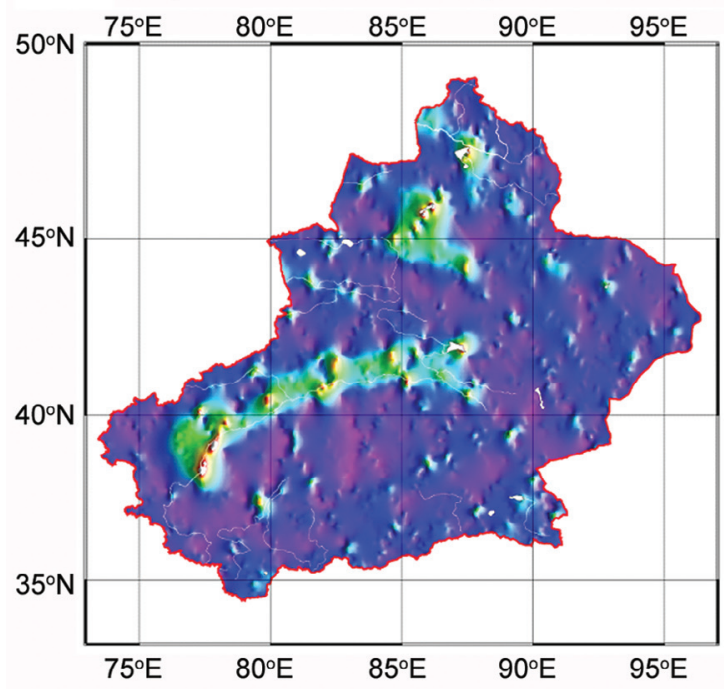

(c) Spatial distribution of sigma0 at C-Ku

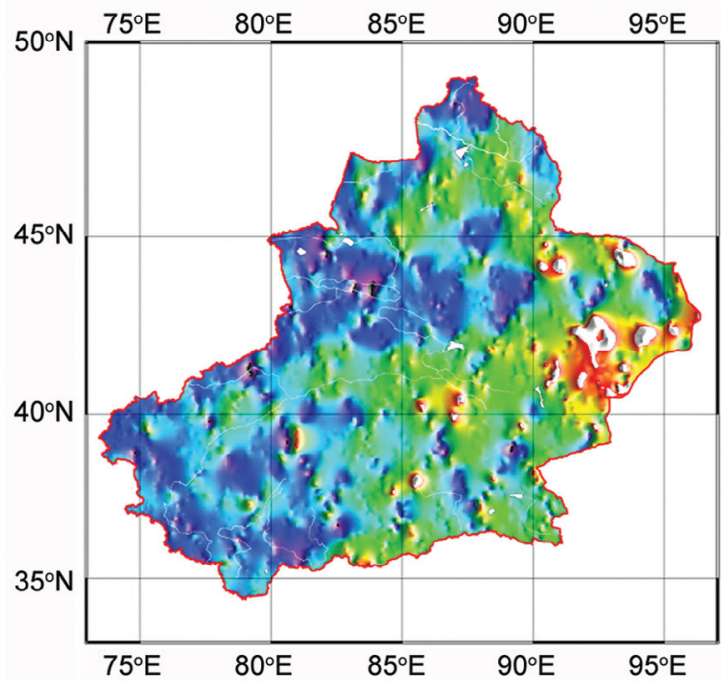

(b)

\section{Spatial distribution of sigma0 at $\mathrm{C}$}
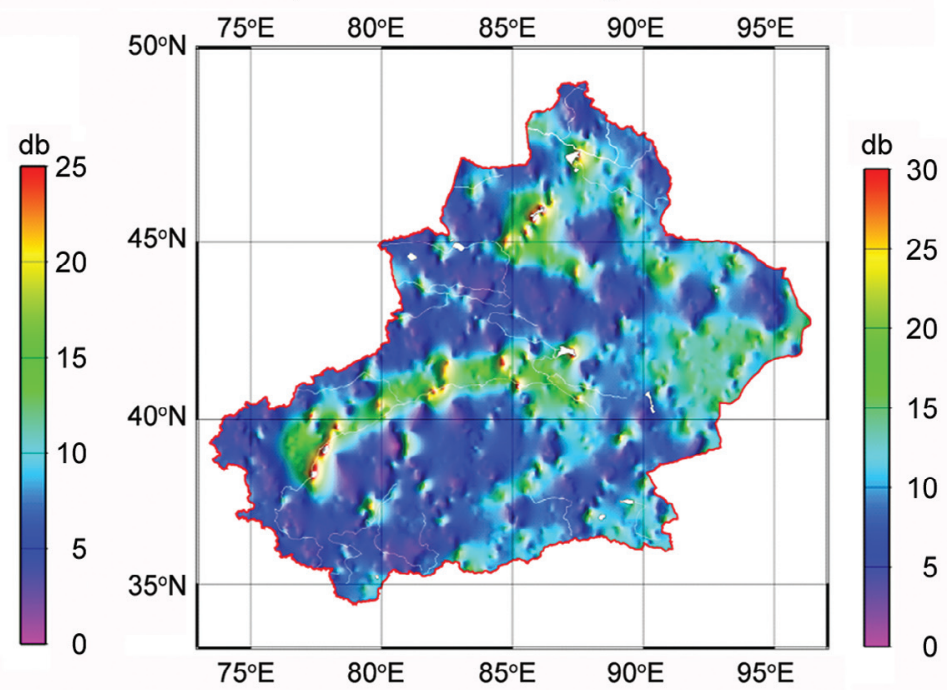

(d) Spatial distribution of sigma0 of $(\mathrm{C}-\mathrm{Ku}) / \mathrm{C}$

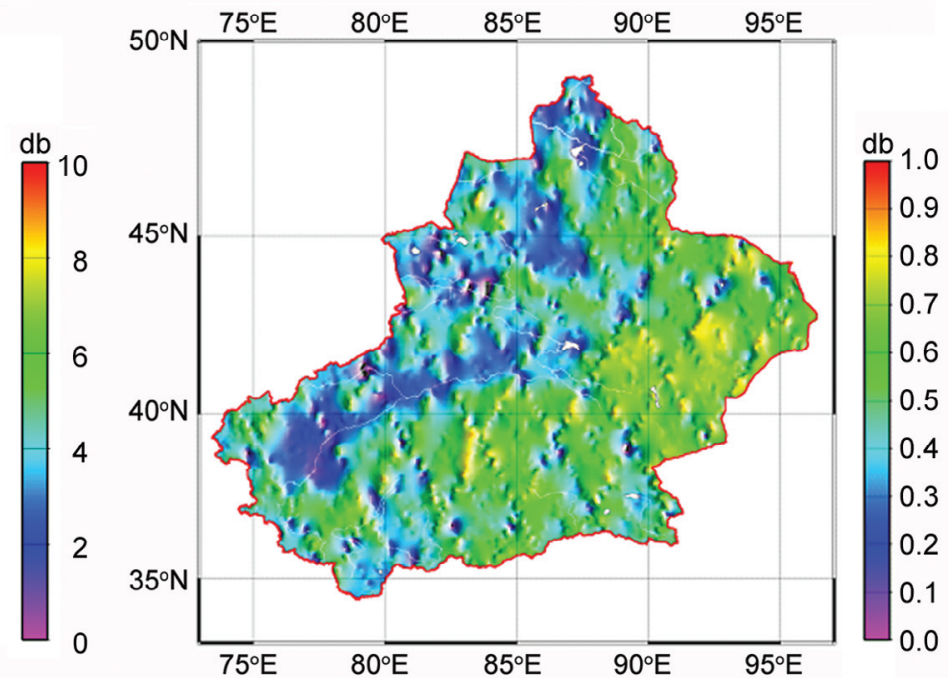

Fig. 2. Spatial distributions of sigma0 over Xinjiang at bands $\mathrm{Ku}(\mathrm{a})$, and $\mathrm{C}(\mathrm{b})$, their absolute differences (c) and their relative differences (d).

change soil moisture or land vegetation coverage, we think that sigma0 would also shows anomalous signals.

The periods and amplitudes of the sigma0 time series at bands $\mathrm{Ku}$ and $\mathrm{C}$ were calculated using the FFT and the least square spectral analysis methods, respectively, using the mean monthly sigma0 data over 12 years from January 1993 to December 2004 extracted from T/P GDRs. The amplitude implies the magnitude of the seasonal variations. Figure $3 \mathrm{a}$ is the time series of mean monthly sigma 0 values at bands $\mathrm{C}$ and $\mathrm{Ku}$ and their differences, which indicates that synchronized annual variations obviously exist at bands $\mathrm{Ku}$ and C. The FFT results, as shown in Fig. 3b, also prove the presence of semi-annual period that has the lower power than that in the annual period. Thus, we conclude that the primary time series cycle at bands $\mathrm{Ku}$ and $\mathrm{C}$ is the annual period and the minor cycle is the semi-annual period. In addition, the FFT results also imply that the annual power is more significant at band $\mathrm{C}$ than that at band $\mathrm{Ku}$, and the semi-annual power is more significant at band $\mathrm{Ku}$ than that at band $\mathrm{C}$, which may be associated with the sensitive variations of different frequency to the land surface. In Fig. 3c, the yearly mean sigma 0 values present less variation except 1999 only at band C, which may be related to the climate anomaly.

As shown in Fig. 4, the least square method is used to calculate the time series amplitudes at bands $\mathrm{Ku}$ and $\mathrm{C}$ for the annual and semi-annual periods, from which we can find that most areas in Xinjiang have low amplitudes which mean the seasonal variations of sigma0 are not high. The reason is that most of the Xinjiang areas are filled with des- 
erts, Gobi or mountains, e.g., the Taklamakan Desert and the Shunha Gobi, with little rainfall and vegetation due to arid and semi-arid climate so that the land surfaces do not change significantly. Conversely, the Tarim River Basin is an exception because the Tarim River is a seasonal stream depending on the seasonal snow-melt water from the Tianshan, Karakoram and Kunlun mountains. The flood period is in summer when tens of kilometers of land across the river can be inundated. Among the river are wide oases and farmlands with seasonal vegetation, which also contribute to the seasonal variations in the backscatter coefficient. Figure 4 also indicates that the high amplitudes appear in the northern Xinjiang because more precipitation and vegetation are here due to the airflow from the Arctic Ocean, especially over the Irtysh River.

Table 1 lists the mean amplitude in both periods at two bands. The amplitudes of the annual period are larger than those in the semi-annual period for the two bands, which matches the FFT results that the annual is the primary cycle. In addition, although there are large differences between the real sigma0 values for bands $\mathrm{Ku}$ and $\mathrm{C}$, the amplitudes are similar between the two bands for both periods.

\section{TIME SERIES ANALYSIS}

In the following context, considering the characteristics of spatial distributions of sigma0 and the ground tracks of T/P, we select three land types for special analysis, including the Tarim River Basin, the Taklamakan Desert and the Tianshan Mountain.

\subsection{Tarim River Basin}

The Tarim River is the longest continental river in China, depending mainly on melting water from accumulated snow from the high mountains. Along the river is a Green Gallery composed of oases with widespread populus euphratica and other kinds of plants. The vegetation along the river present an obviously vertical distribution, the further away from the river the less vegetations and types of vegetation until only drought resistant vegetation can survive. The three sources of the Tarim River are the Hotan River, Aksu River and Yarkand River, converging in the Aksu Prefecture to form the mainstream Tarim River that disappears east of the Tarim. The Tarim River network is

(a)

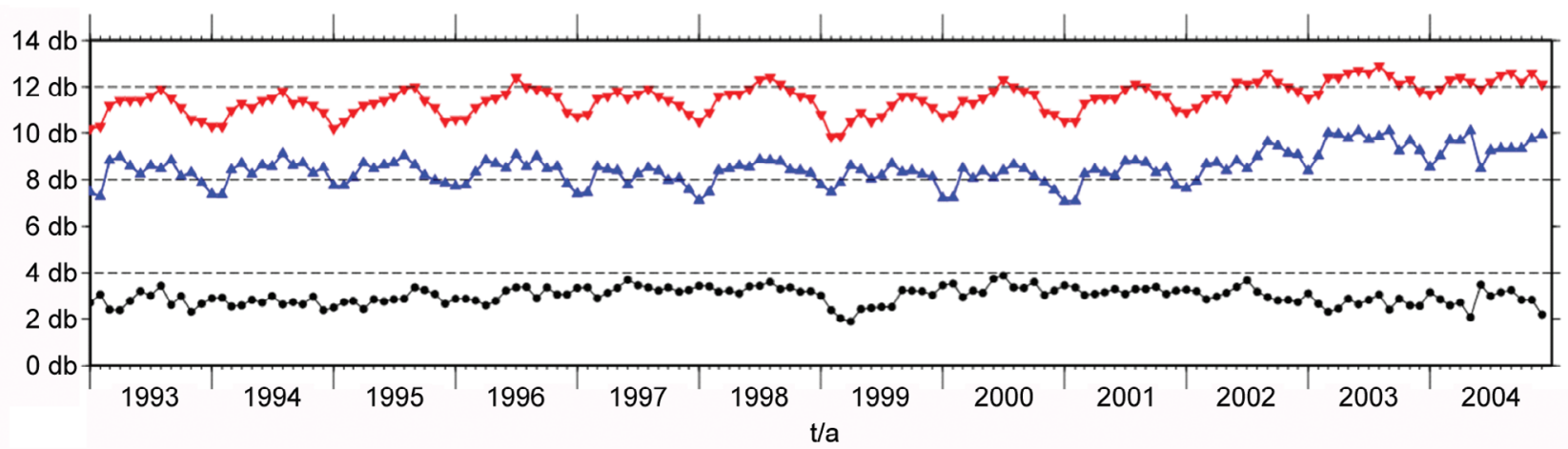

(b)

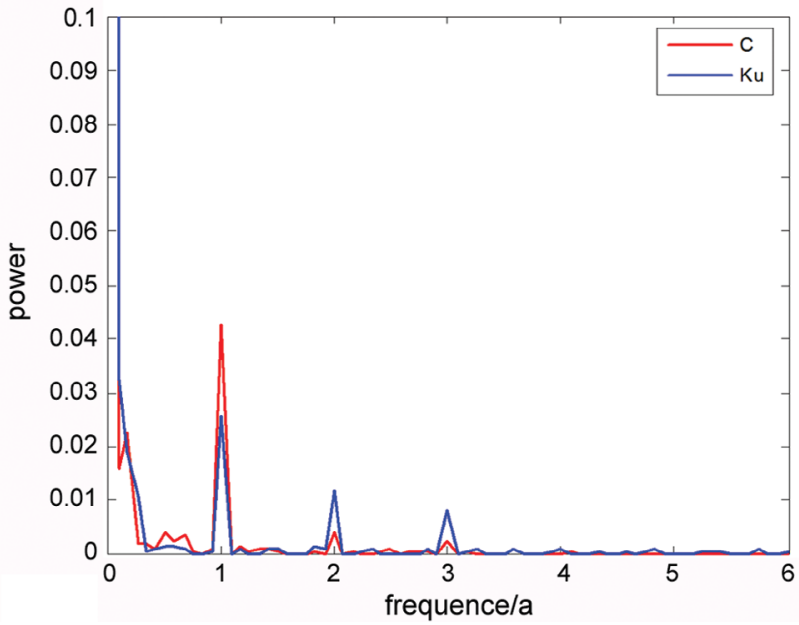

(c)

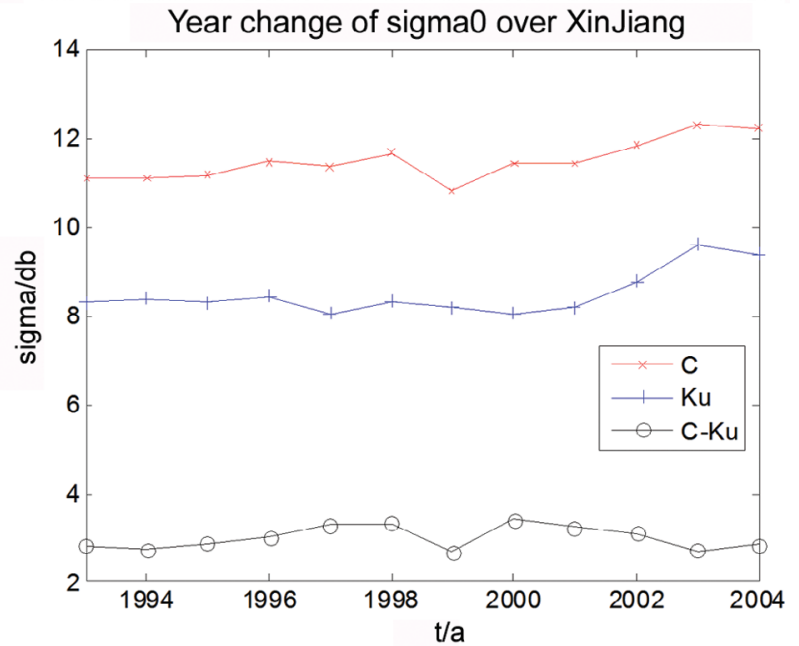

Fig. 3. Time series of monthly mean values of sigma0 at bands $\mathrm{C}$ and $\mathrm{Ku}$, as well as the difference values (a), in which the red line is for band $\mathrm{C}$, the blue line for band $\mathrm{Ku}$ and black line for their difference. The FFT result of the time series at bands Ku and $\mathrm{C}$ (b). The yearly mean values time series of sigma 0 at bands $\mathrm{C}, \mathrm{Ku}$ and their difference (c). 
(a) Amplitude of annual variations at $\mathrm{Ku}$

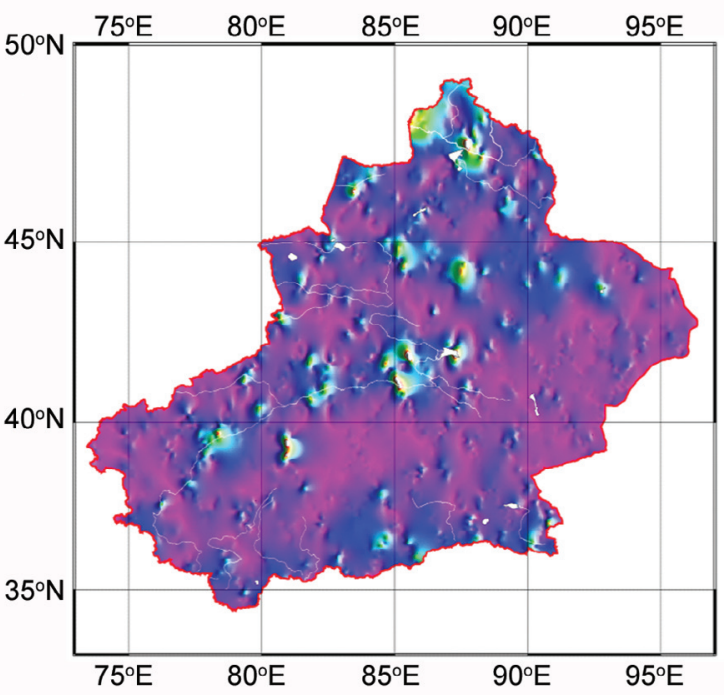

(c) Amplitude of annual variations at $\mathrm{C}$

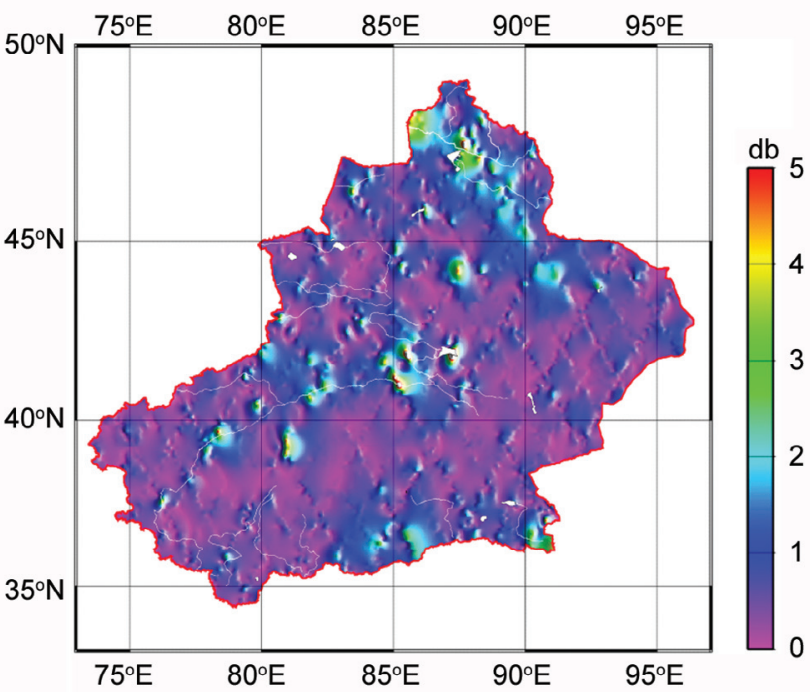

(b) Amplitude of semi-annual variations at $\mathrm{Ku}$

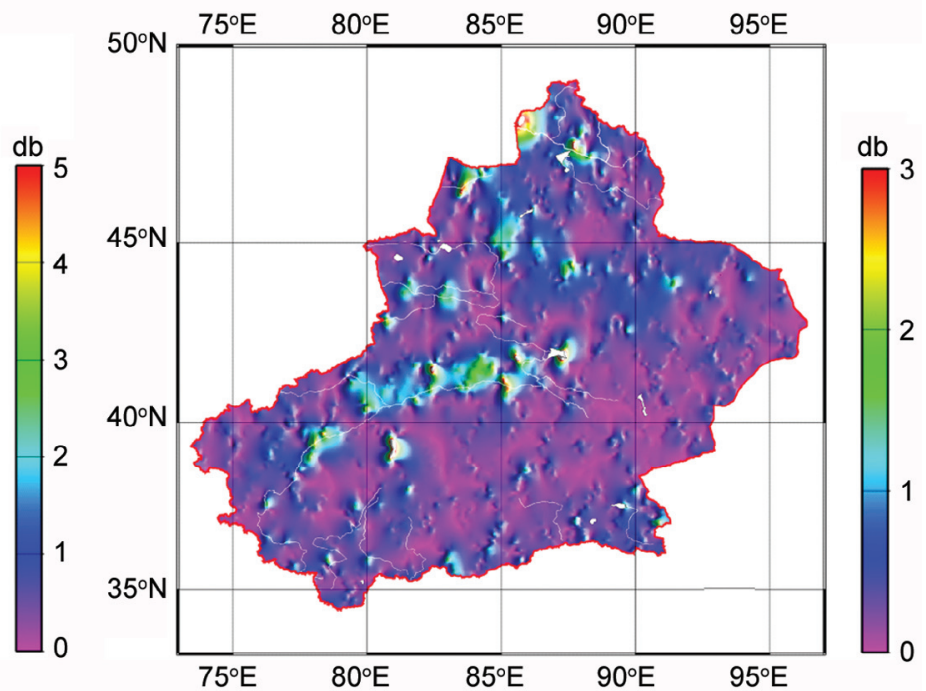

(d) Amplitude of annual variations at $\mathrm{C}$

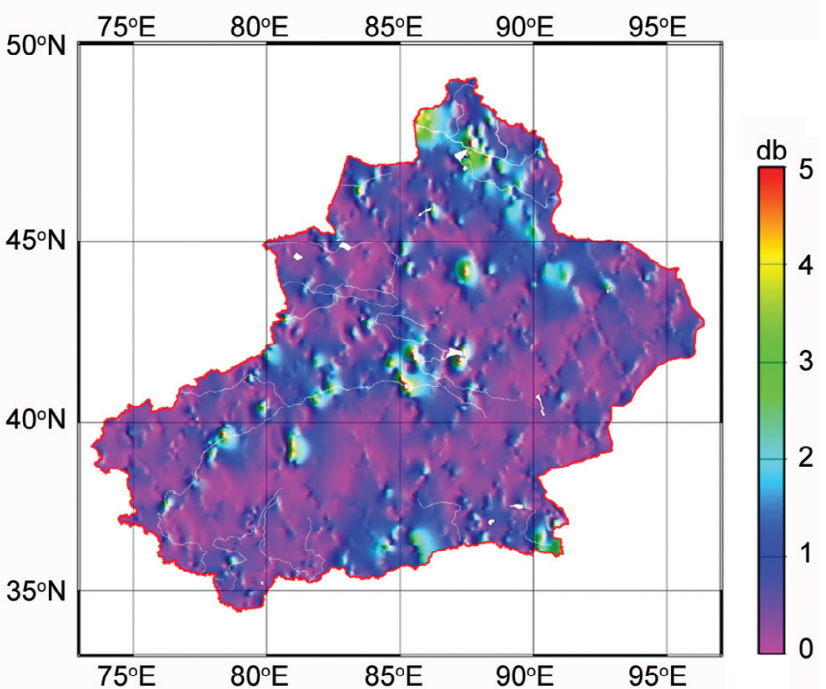

Fig. 4. The amplitudes of sigma0 time series of annual and semi-annual periods at bands $\mathrm{Ku}$ and $\mathrm{C}$.

shown in Fig. 5. Considering variations in different parts of the Tarim River, it is unsuitable to lump them together. Thus, we divide the river into the source, mainstream and the end reaches of the river to study the sigma0 time series, respectively.

\subsubsection{Source of the Tarim River}

\section{(A) The Hotan River}

The Hotan River runs through the Taklamakan Desert and is an intermittent river with nearly no water inflows into the mainstream of Tarim River except sometimes in the flood period. Figure 6 shows the sigma0 time series at two bands over the upper reaches of the Hotan River containing a crossover point of $\mathrm{T} / \mathrm{P}$ ground tracks, indicating that a
Table 1. Statistics of amplitudes at bands Ku and C (unit in db).

\begin{tabular}{|ccc|}
\hline Band & Annual amplitude & Semi-annual amplitude \\
\hline $\mathrm{Ku}($ mean $)$ & 0.62 & 0.40 \\
$\mathrm{C}$ (mean) & 0.70 & 0.43 \\
\hline
\end{tabular}

maximum point appears in summer every year which rises and drops obviously. Generally, it rises quickly in June when the accumulated snow on Kunlun Mountain thaws causing increasing river width and soil moisture in the Hotan River Basin. The sigma0 begins to drop in August because the amount of thawing snow meets its maxima and the evaporation capacity increases strongly. The time series different values for bands $\mathrm{C}$ and $\mathrm{Ku}$ shows a trough when the sigma0 
values at bands $\mathrm{C}$ and $\mathrm{Ku}$ are at the highest point (year 1997 is an exception). This is related to the penetration difference of two frequencies, bands $\mathrm{C}$ and $\mathrm{Ku}$ are lower over the wet land and higher over the dry land. In 1997, the sigma0 values at the two bands were lower than in other years, which indicates that the river discharge was small and the amount of thawing snow was lower in this year. The strongest El
Nino in the $20^{\text {th }}$ century took place in December, 1997 (Cox and Chao 2002; Hwang et al. 2005).

In addition, a light sigma0 fluctuation occurs in spring every year, which may be associated with the balance between the river discharge from snow thawing and the evaporation capacity. In the early spring when the evaporation capacity is not evident, the snow on the mountains begins

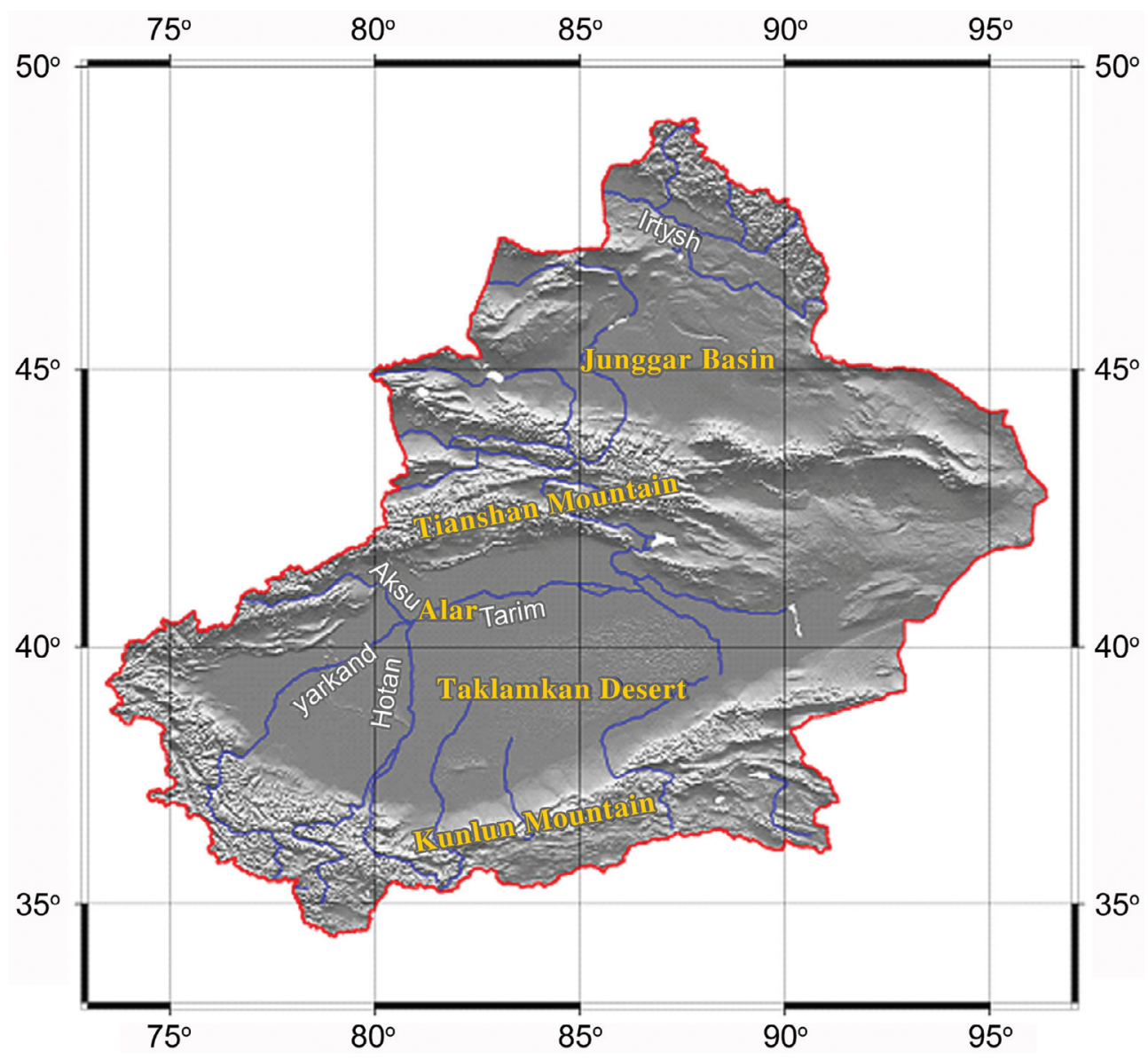

Fig. 5. The river network in the Tarim basin.

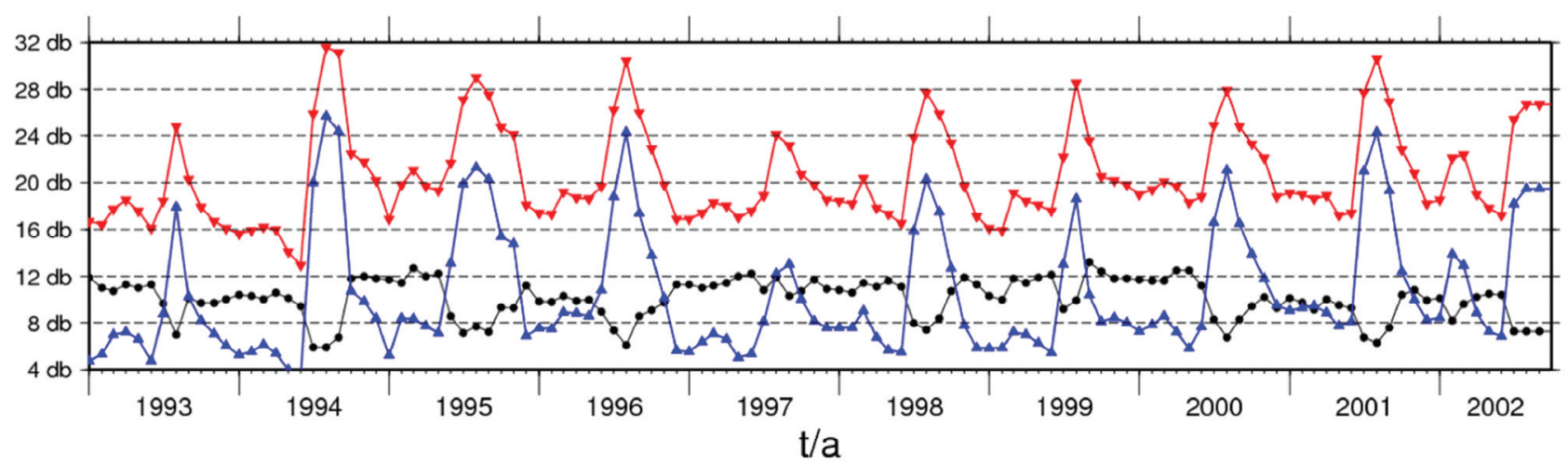

Fig. 6. Time series of sigma0 over the Hotan river $\left(38.95-39.50^{\circ} \mathrm{N}, 80.85-81^{\circ} \mathrm{E}\right)$. Red line is for band $\mathrm{C}$, blue line for band $\mathrm{Ku}$ and black line for their differences. 
to thaw and increases the river discharge and soil moisture. Thus, the sigma0 values have a rising trend. As the temperature increases over land, the evaporation capacity has a greater position than the increasing of soil moisture, because there is little snow thaw in the high mountains. Thus, the sigma 0 values show a light drop trend. In addition to the flood period in summer, most times each year present high difference in $\mathrm{Ku}$ and $\mathrm{C}$ band values, which have the characteristics of arid areas. The statistics reveal that the mean sigma0 values of bands $\mathrm{Ku}$ and $\mathrm{C}$ are 10.44 and $20.54 \mathrm{db}$, respectively, with a high difference value of $10.10 \mathrm{db}$. And the standard deviation (STD) values for bands $\mathrm{Ku}$ and $\mathrm{C}$ are 5.29 and $4.00 \mathrm{db}$ which are significantly high due to the clearly seasonal feature of Hotan River.

\section{(B) Aksu River}

Of the three source rivers (Aksu, Yarkand, Khotan), only the Aksu River flows into the Tarim year-round. It is the Tarim's most important tributary, supplying $70-80$ percent of its water volume. Considering the limit of $\mathrm{T} / \mathrm{P}$ ground tracks over the river basin, we only selected the Toshkan River, the main tributary of the Aksu River, for the time series analysis. The Toshkan River has its sources in the mountains south of the Kyrgyzstani city of Naryn and then flows towards the east and into the Xinjiang, China. It continues to east, running parallel to the Tianshan Mountain, until its confluence with the Aksu River (http:// no.wikipedia.org/wiki/Toshkan).

Figure 7 shows that the seasonal sigma0 variations are not obvious in this area. As a whole, sigma0 reaches its maximum in summer and minimum in winter. Beside 1995, the sigma 0 values at bands $\mathrm{Ku}$ and $\mathrm{C}$ are close to each other. The average sigma 0 values at bands $\mathrm{Ku}$ and $\mathrm{C}$ and their difference are $16.24,16.43$, and $0.21 \mathrm{db}$, respectively, which implies that the mean difference value for bands $\mathrm{Ku}$ and $\mathrm{C}$ is very small. This also indicates that this river basin is moister than the Hotan River Basin, which is related to the Aksu River discharge.

\section{(C) Yarkand River}

The Yarkand River is one of headstreams of the Tarim River. It is approximately $970 \mathrm{~km}$ in length. The river originates in the Karakoram Range, south of Kashgar Prefecture. The billowy hill-torrent flows out of the Kunlun Gorge and flows north, forming a large amount of branches distributed over the alluvial fan and irrigating the Yarkand oases, which is one of the largest oases in Xinjiang. We separated it into three parts for analysis in consideration of the T/P ground track and the different characteristics.

Figure 8 indicates that the sigma0 values and seasonal variations over different parts of the river basin yield significant variations. We provide statistical information for the different reaches in Table 2.

From Table 2 we can find that the highest sigma0 values at bands $\mathrm{C}$ and $\mathrm{Ku}$ are in the middle reach and upper reach. The lowest values are in the down reach. The highest standard deviations at two bands are in the down reach, the second is the middle reach and the lowest is the upper reach. This is associated with the oases distribution and the discharge of different river reaches. With the abundant discharge the oases are well developed and the soil moisture is high in the upper reach. The sigma0 values are therefore high. However, the agriculture is undeveloped due to its large topography fluctuations and land surface coverage is much stabler than the middle part and the lower part of the river. The standard deviations over the upper area are lowest. For the middle river basin reach, the river basin is much wider, the topography turns more flat and the agriculture is developed. The sigma0 and standard deviations are highest here. Because water is consumed for agriculture, water rarely flows into the down reach and the soil is dry, which leads to the lowest sigma0 values. Oases in the down reach are

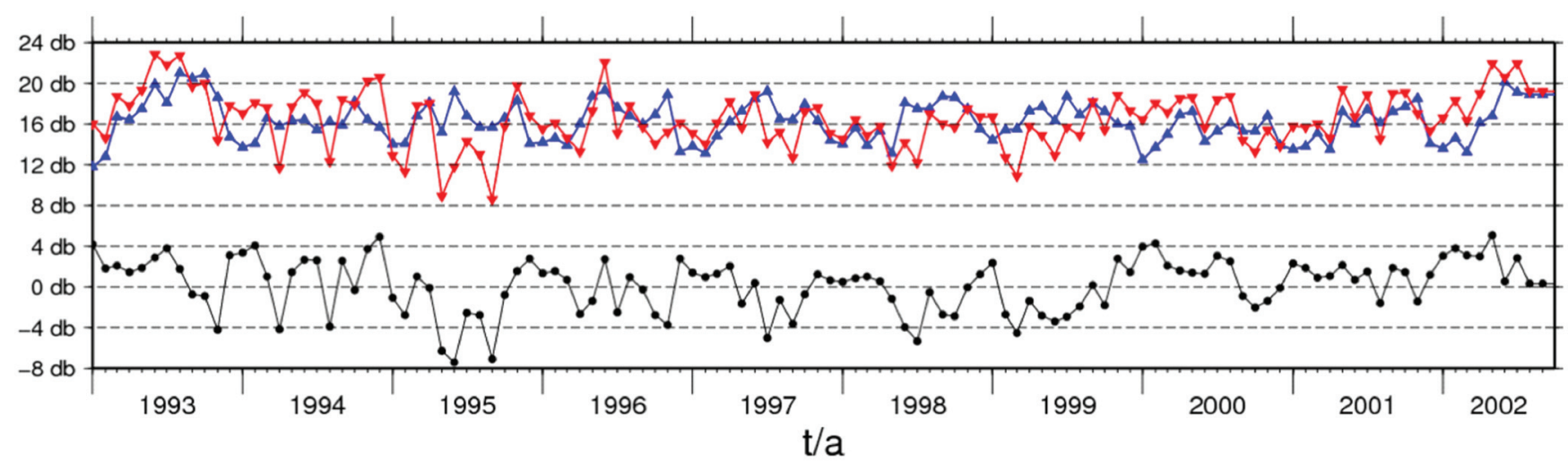

Fig. 7. Time series of sigma0 over the Aksu River $\left(41.17-43^{\circ} \mathrm{N}, 79.17-79.57^{\circ} \mathrm{E}\right)$. Red line is for band $\mathrm{C}$, blue line for band Ku and black line for their differences. 
(a)

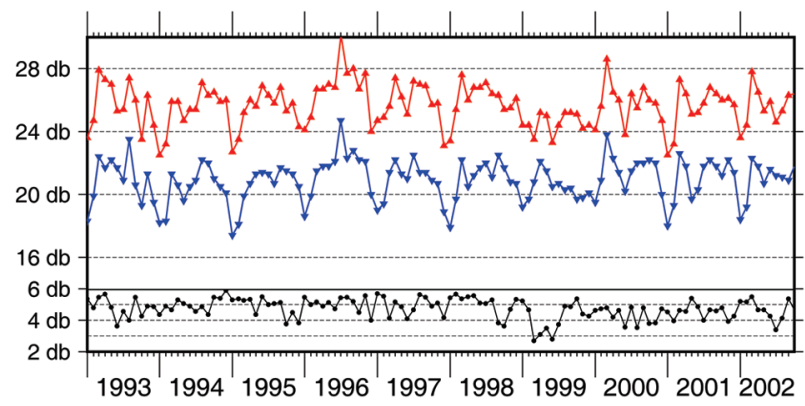

(c)

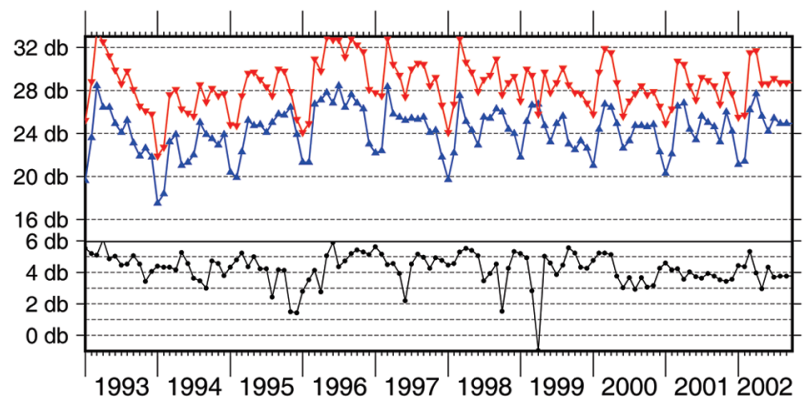

(b)

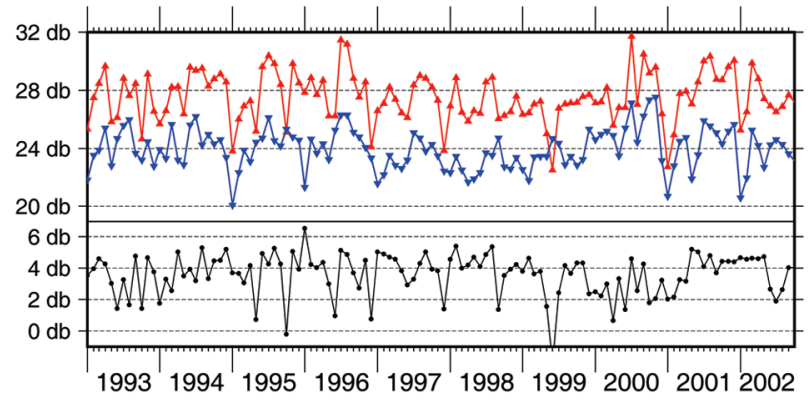

(d)

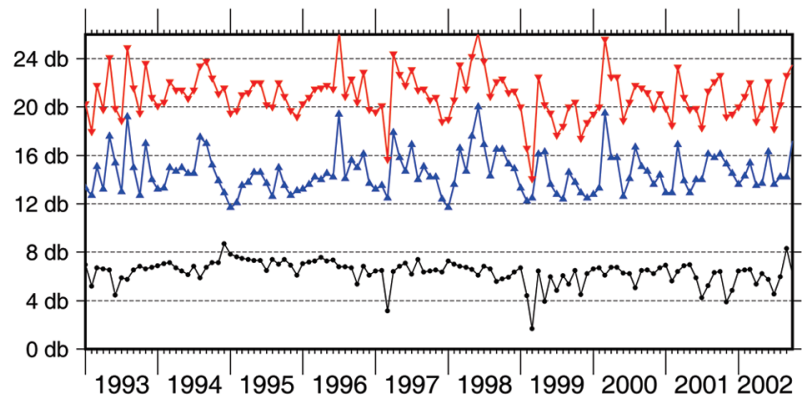

Fig. 8. (a) Time series of sigma0 over the whole Yarkand River Basin; (b) upper stream $\left(38-38.5^{\circ} \mathrm{N}, 77-77.5^{\circ} \mathrm{E}\right)$; (c) middle stream $\left(39-39.5^{\circ} \mathrm{N}\right.$, $\left.77.75-78.25^{\circ} \mathrm{E}\right)$; (d) downstream $\left(40-40.5^{\circ} \mathrm{N}, 79.75-80.35^{\circ} \mathrm{E}\right)$. Red line is for band C, blue line for band $\mathrm{Ku}$ and black line for their differences.

Table 2. Statistics of sigma0 over different reaches of the Yarkand River (unit in db).

\begin{tabular}{|c|c|cccc|}
\hline \multicolumn{2}{|c|}{} & Whole reach & Upper reach & Middle reach & Down reach \\
\hline \multirow{2}{*}{ Ku } & Mean & 20.99 & 23.39 & 24.36 & 15.23 \\
& STD & 1.45 & 1.85 & 1.97 & 2.13 \\
\hline \multirow{2}{*}{ C } & Mean & 25.79 & 27.30 & 28.51 & 21.57 \\
& STD & 1.98 & 1.78 & 2.06 & 2.23 \\
\hline \multicolumn{2}{|c|}{ Difference } & 4.80 & 3.60 & 4.16 & 6.34 \\
\hline
\end{tabular}

degenerated for the excessive water utilization in the upper reaches, which causes the climate to be much drier. Thus, the sigma0 differences for bands $\mathrm{C}$ and $\mathrm{Ku}$ are the highest in the down stream.

\subsubsection{The Middle Reach of Tarim River}

The Tarim River starts from the Alar where three tributaries converge together and disappears at the lower Tarim Basin which is an arid plain composed of alluvium and lake sediments bordered by massive mountain ranges (http:// en.wikipedia.org/wiki/Tarim River).

Figure 9 shows the sigma0 time series over the whole and upper, middle and lower parts of the river basin. Figure 10 presents a comparison of sigma 0 at bands $\mathrm{Ku}$ or $\mathrm{C}$ over the Tarim mainstream. We find that different parts of the river basin show clearly different characteristics, espe- cially the middle river basin with stronger signals in summer at both bands than the other parts. The statistical information in Table 3 indicates that the standard deviation in the middle river basin is largest, three times that over the lower parts, which is related to the wide rive bank in the flood period. In summer, the river level rises up and inundates both sides of the river bank leading to increasing soil moisture. In the upper reach the sigma0 values are larger over the lower reach and middle reaches except in summer. Table 3 shows that the average sigma0 values over the upper area of the mainstream are largest. The reason is that the river water is more abundant than at other reaches although the river banks of the upper reach are not as wide as the middle reach. For the lower reach, the river discharge becomes rare and the riverbed is generally in drought situation. Even in the flood period in summer the river discharge is not much. In addition, the different values for bands $\mathrm{C}$ and $\mathrm{Ku}$ are 
(a)

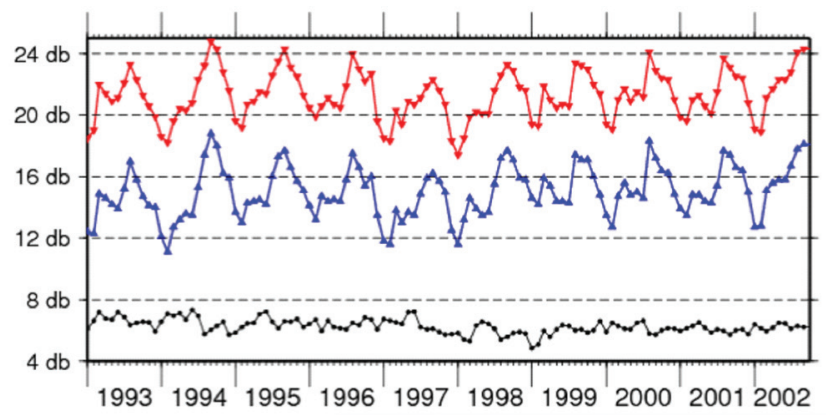

(c)

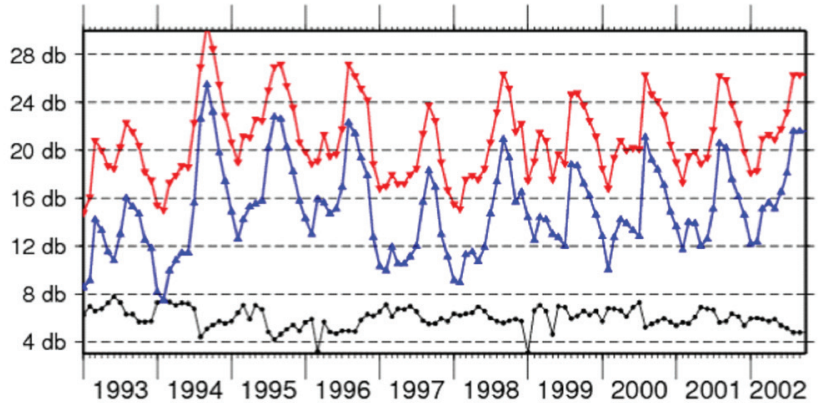

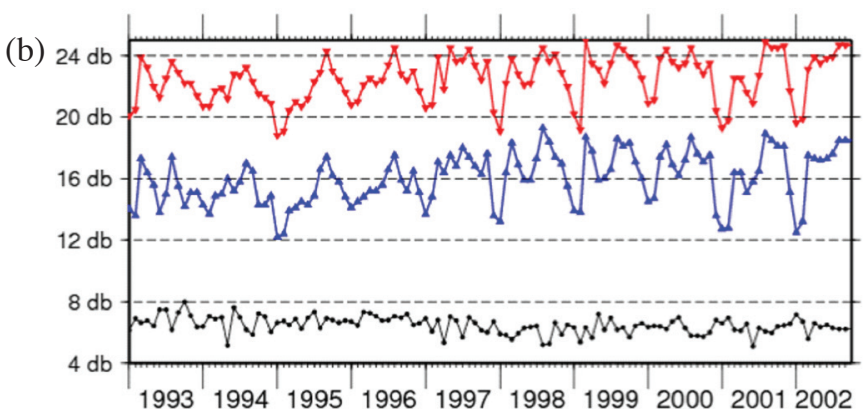

(d) $24 \mathrm{db}$

Fig. 9. (a) Time series of sigma0 over the whole Tarim River Basin; (b) upper stream $\left(40.70-41.50^{\circ} \mathrm{N}, 81.75-82.75^{\circ} \mathrm{E}\right)$; (c) middle stream $(41-$ $\left.41.50^{\circ} \mathrm{N}, 84.75-85.25^{\circ} \mathrm{E}\right)$; (d) downstream $\left(40.55-41^{\circ} \mathrm{N}, 87.40-87.55^{\circ} \mathrm{E}\right)$. Red line is for band $\mathrm{C}$, blue line for band $\mathrm{Ku}$ and black line for their differences.

(a)
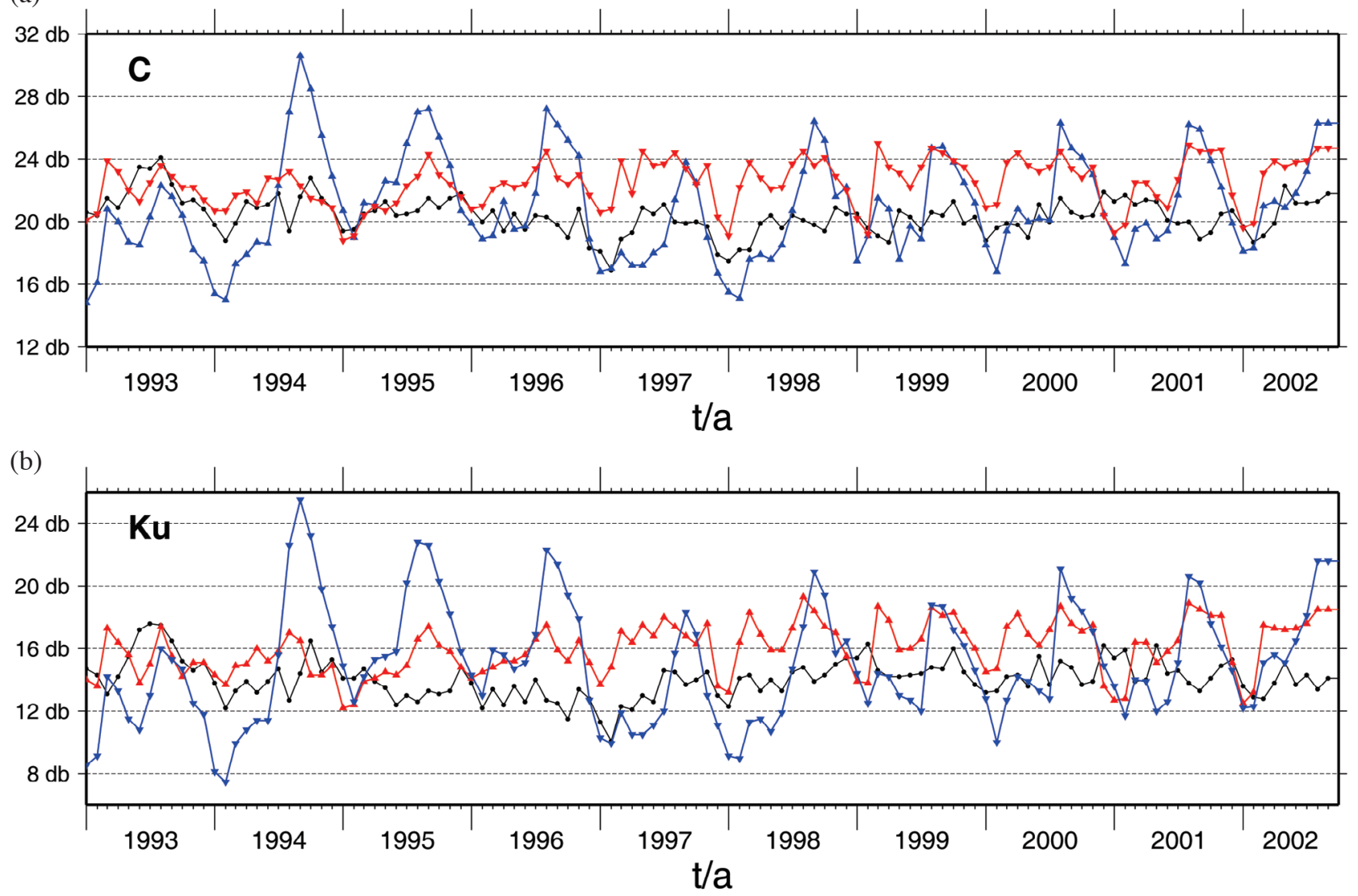

Fig. 10. Comparisons of sigma0 at C (a) and Ku (b) over the upper reach (red), middle reach (blue) and down reach (black) of the Tarim River. 
Table 3. Statistics of sigma0 over different reaches of the Tarim mainstream (unit in $\mathrm{db}$ ).

\begin{tabular}{|c|c|rrrr|}
\hline \multicolumn{2}{|c|}{} & Whole & Upper & Middle & Lower \\
\hline \multirow{2}{*}{ Ku } & Mean & 14.97 & 15.96 & 14.90 & 14.06 \\
& STD & 1.62 & 1.66 & 3.71 & 1.24 \\
\hline \multirow{2}{*}{ C } & Mean & 21.24 & 22.43 & 20.91 & 20.36 \\
& STD & 1.54 & 1.50 & 3.26 & 1.19 \\
\hline \multicolumn{2}{|c}{ Difference } & 6.26 & 6.47 & 6.01 & 6.31 \\
\hline
\end{tabular}

significant, more than $6 \mathrm{db}$ over all river reaches, which implies that the mainstream basin is relatively dry.

\subsection{Tianshan Mountain}

The T/P satellite passes through Tomur Peak and Khan Tengri Peak, which are the highest and second-highest mountains in the Tianshan Mountain range, respectively. These mountains are covered by snow and ice all year. The largest contemporary glaciers in China are also here.

From Fig. 11 we can see that the high sigma0 values are generally present in summer (July, August and September), while the lower and stable values are present in winter (October to February of next year). Some anomalies are also shown, such as sigma 0 values at band $\mathrm{Ku}$ being the highest in winter but that at band C are normal. In 1997 the yearly sigma 0 variations at the two bands were less than $2 \mathrm{db}$, which may be associated with the snow precipitation and temperature this year under global/regional climate change effects. The trends calculated using the least square method for bands $\mathrm{Ku}$ and $\mathrm{C}$ and their differences are $-0.14,0.27$, and $0.40 \mathrm{db}$, respectively. The difference shows an obvious increase after 1999, which may be related to melting of snow and ice due to the sensitive response of high mountains to global warming.

\subsection{Taklimakan Desert}

The Taklimakan Desert is located in Xinjiang, China. It is bounded by the Kunlun Mountains to the south, the Pamir Mountains to the west and the Tianshan Mountain to the north. It is the best suitable natural place on the Earth for altimeter data calibration and validation (Berry et al. 2000). Here we only selected one typical area including a crossover point to analyze the sigma0 time series.

Figure 12 shows the sigma 0 time series in an area of the Taklimakan Desert. The statistical information of the sigma0 time series indicates that the average values for bands $\mathrm{Ku}$ and $\mathrm{C}$ are 3.06 and $8.62 \mathrm{db}$, and the STDs for bands $\mathrm{Ku}$ and $\mathrm{C}$ are 0.44 and $0.46 \mathrm{db}$. The first characteristics of sigma 0 over Taklimakan is the significant difference between bands $\mathrm{C}$ and $\mathrm{Ku}$, which relate the different penetra- tion ability of radar pulses for bands $\mathrm{Ku}$ and $\mathrm{C}$. The second characteristic is that the sigma 0 values are clearly stable and the seasonal variation is not evident at all due to the slightly seasonal variation in the desert. This is the reason Taklimakan is the best natural place for altimeter data calibration and validation.

\section{CORRELATION BETWEEN BRIGHTNESS TEM- PERATURE AND SIGMAO}

The TMR on the T/P satellite measures the sea surface microwave emissivity (brightness temperatures) as well as the land surface at three frequencies $(18,21$, and $37 \mathrm{GHz})$ to provide the total water-vapor content in the troposphere along the altimeter beam. The $21 \mathrm{GHz}$ channel is the primary channel for water-vapor measurement. The brightness temperature value is widely used to calculate the range measurement troposphere correlation for radar altimetry. The brightness temperature data for $21 \mathrm{GHz}$ over Xinjiang were derived from the GDR-M dataset with the same time span as the sigma0 from January 1993 to December 2004. The relationship between the backscatter change and the brightness temperature change can indicate the influence of watervapor indirectly.

As shown in Fig. 13, it is clear that inter-annual changes in brightness temperature exist, which is familiar with the sigma0 time series. The correlation coefficients for brightness temperature values and sigma 0 values at bands $\mathrm{C}$ and $\mathrm{Ku}$ are 0.59 and 0.46 , respectively, which are strongly linear correlations.

The spatial distribution of the mean brightness temperature values in 1994 is given in Fig. 14. Some key characteristics are shown such as the values are high over desert or arid areas and low in mountain areas.

\section{DISCUSSION AND CONCLUSIONS}

The economic development in Xinjiang has made great progress since the reform and opening, but the environment and resources have been destroyed to different extents, especially the decrease of wetlands around the Tarim River, the so-called mother river of Xinjiang. The intensification 
of desertification downstream is evident. The trend of climate and environmental change over Xinjiang relates to economic development, national unity and social stability, but also the implementation of national environmental policy in western China. Using satellite observations to carry out scientific observations over a long time over Xinjiang, such as the Taklimakan Desert, the Tarim River Oases, the
Tianshan Mountain and other important regions, has great significance for monitoring the spatial and temporal distributions of land surface variations under the effects of climate change.

This study used T/P sigma0 data for 12 years to investigate the land surface variations. This is a new and challenging research field for land altimetry technique, but from

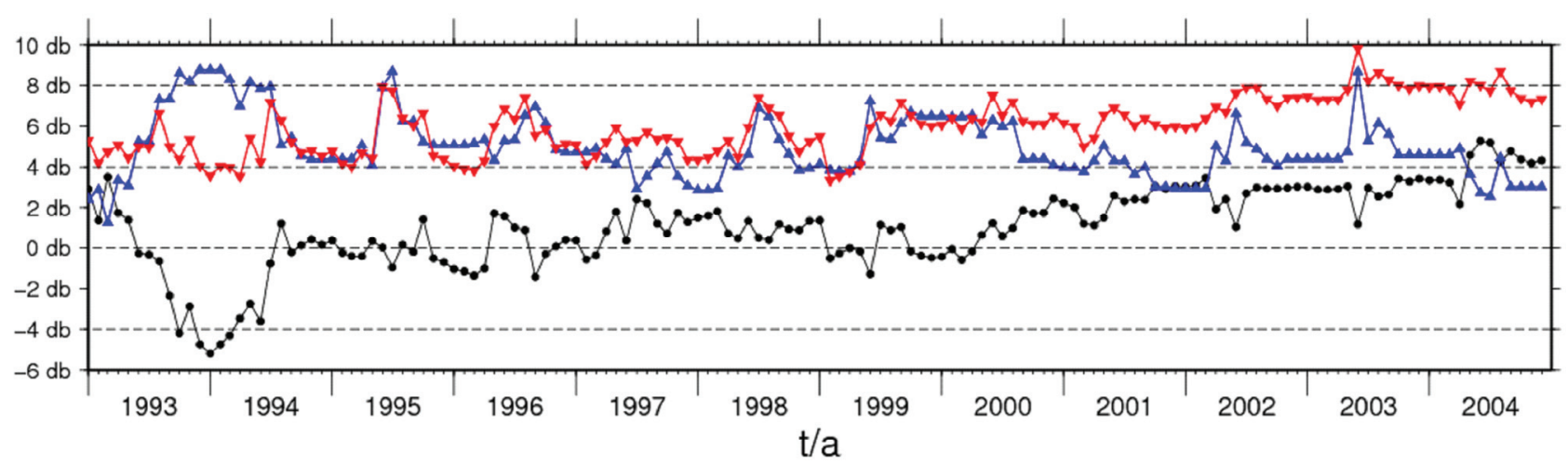

Fig. 11. Time series of sigma0 over Tianshan Mountain $\left(41.70-42.50^{\circ} \mathrm{N}, 79.50-80.50^{\circ} \mathrm{E}\right)$. Red line is for band $\mathrm{C}$, blue line for band $\mathrm{Ku}$ and black line for their differences.

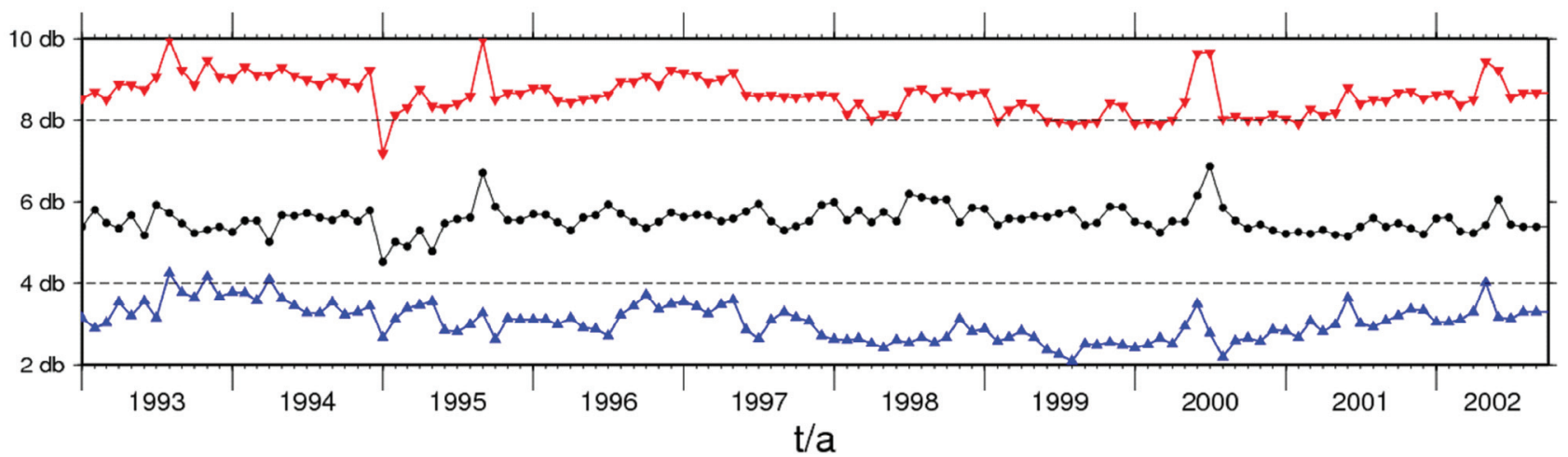

Fig. 12. Time series of sigma0 over Taklimakan Desert $\left(38.90-39.50^{\circ} \mathrm{N}, 83.30-83.90^{\circ} \mathrm{E}\right)$. Red line is for band $\mathrm{C}$, blue line for band Ku and black line for their differences.

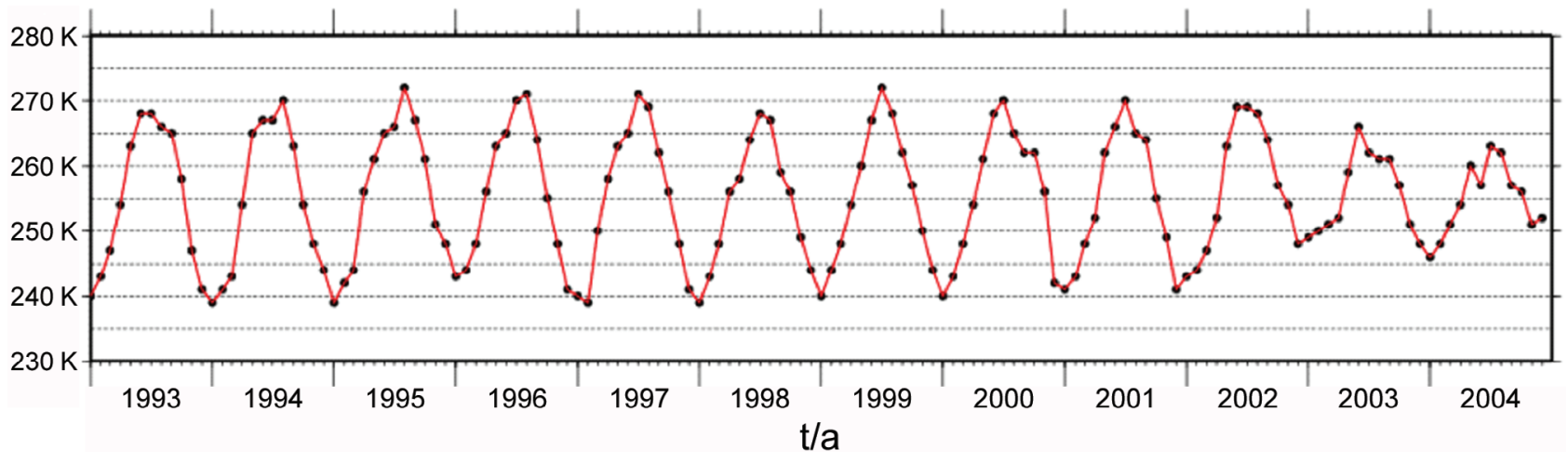

Fig. 13. Time series of brightness temperature over Xinjiang. 


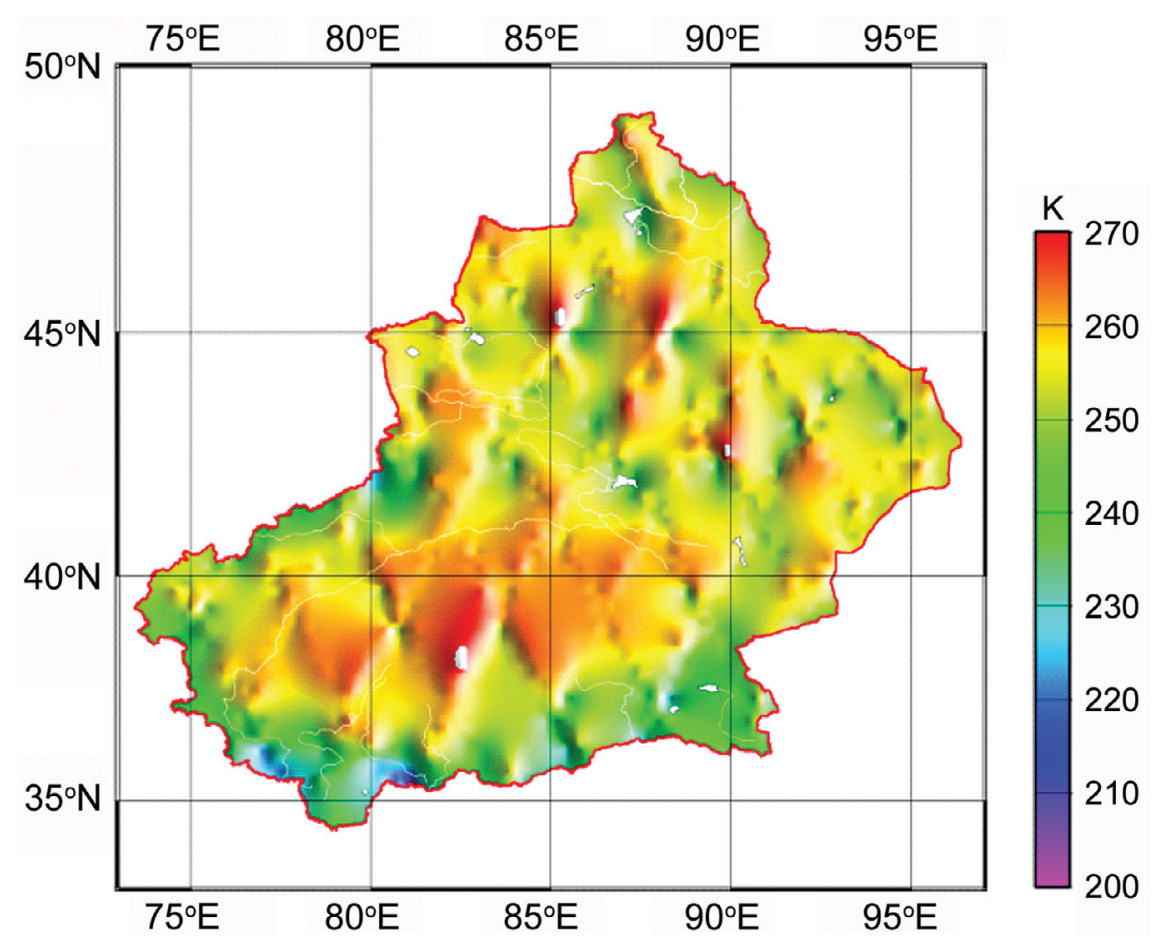

Fig. 14. Spatial distribution of brightness temperature over Xinjiang.

our study some significant results are revealed. Firstly, the spatial distributions of mean sigma0 at bands $\mathrm{Ku}$ and $\mathrm{C}$ indicate that the backscatter coefficients are sensitive to the oases along the Tarim River and one can clearly distinguish the river basin. Due to the topography anomalies, mountains like the Tianshan Mountain can yield lower sigma0 values and can also be distinguished in the spatial distributions at both bands (much clearer at $\mathrm{C}$ band). The difference in climate and environment between the northern and southern Xinjiang can be reflected by sigma0. The absolute and relative differences of sigma 0 values at bands $\mathrm{Ku}$ and $\mathrm{C}$ over Xinjiang were calculated to study the penetration difference for these two bands. The results indicate that the absolute difference in the Shunha Gobi is high and the relative difference in the Taklimakan Desert is also high. The cycles for seasonal variations at both bands are annual and semi-annual using the FFT method. The amplitude distributions for two cycles were calculated using the least squares method, which indicates that most of Xinjiang exhibits lower amplitude values beside some large river basins as the Tarim River Basin and the Irtysh River Basin due to the dry environment and the widespread desert and Gobi over Xinjiang.

The Tarim River was separated into several parts to analyze sigma0 time series and the differences in river reaches, such as the soil moisture, can be evidently revealed, indicating that the radar altimeter is a power tool to monitor the seasonal river basin. Sigma0 values at bands $\mathrm{Ku}$ and $\mathrm{C}$ in the Taklamakan Desert were low and stable but with significant difference values between bands $\mathrm{Ku}$ and $\mathrm{C}$, which is accordant to former works (Guo et al. 2012). Time series at bands $\mathrm{Ku}$ and $\mathrm{C}$ shows opposite trends over the Tomur and Khan Tengri in Tianshan Mountain, implying that the snow and ice properties may be changed under the effects of climate change. A strong linear correlation between the sigma0 time series at two bands and the brightness temperature over Xinjiang were found, which indicates that an inner relationship exists between sigma0 and the brightness temperature.

More studies are needed for land surface monitoring research using backscatter coefficients from long time period radar altimeter runtimes. Building sigma0 model for soil moisture, land surface roughness and vegetation is especially important work for better understanding the connection between backscatter coefficients and natural land characteristics. With radar altimeter development applying SAR technology to the altimeter and an altimeter constellation plan, the spatial distribution database will be greatly improved, which is very important for land applications using radar altimeters. Accompanying remote satellite imaging or other microwave satellite sensors, the land surface variations caused by seasonal changes or climate change can be detected more clearly with the satellite radar altimetric technique. 
Acknowledgements We thank the anonymous reviewers for their thoughtful comments. We are very grateful to AVISO for providing T/P data. This study is partially supported by the National Natural Science Foundation of China (grant No. 40974004 and 40774009), the Key Laboratory of Mapping from Space of NASMG, China (grant No. K201103), and the R\&I Team Support Program and Graduate Innovation Fund of SDUST, China (grant No. YCB110010).

\section{REFERENCES}

Berry, P. A. M., 2000: Topography from land radar altimeter data: possibilities and restrictions. Phys. Chem. Earth, Part A, 25, 81-88, doi: 10.1016/S1464-1895(00)000 14-4. [Link]

Berry, P. A. M., R. A. Pinnock, and H. K. Wilson, 2000: Land calibration and monitoring of ENVISAT RA-2 sigma0. Proceedings of the ERS-ENVISAT Symposium, Gothenburg, Sweden, CD-Rom SP-461.

Bramer, S. M. C., P. A. M. Berry, and C. P. D. Johnson, 2004: Analysis of ENVISAT RA-2 backscatter over natural land calibration targets. Proceedings of the 2004 Envisat \& ERS Symposium (ESA SP-572), Salzburg, Austria.

Brown, G. S., H. R. Stanley, and N. A. Roy, 1981: The wind speed measurement capacity of space borne radar altimetry. IEEE J. Ocean. Eng., OE6, 59-63.

Campos, I. O., F. Mercier, C. Maheu, G. Cochonneau, P. Kosuth, D. Blitzkow, and A. Cazenave, 2001: Temporal variations of river basin waters from Topex/Poseidon satellite altimetry. Application to the Amazon basin. Earth Planet. Sci., 333, 633-643, doi: 10.1016/S1 251-8050(01)01688-3. [Link]

Chang, X., C. Zhang, H. Wen, and J. Li, 2008: Gravity anomaly and satellite altimetry in the China seas: Applications to geodynamics. Terr. Atmos. Ocean. Sci., 19, 83-92, doi: 10.3319/TAO.2008.19.1-2.83(SA). [Link]

Chelton, D. B. and P. J. Mccabe, 1985: A review of satellite altimeter measurement of sea surface wind speed: With a proposed new algorithm. J. Geophys. Res., 90, 4707-4720, doi: 10.1029/JC090iC03p04707. [Link]

Chelton, D. B., J. C. Ries, B. J. Haines, L. L. Fu, and P. S. Callahan, 2001: Satellite altimetry. In: Fu, L. L. and A. Cazenave (Eds.), Satellite Altimetry and Earth Sciences, A Handbook of Techniques and Applications, International Geophysics Series Volume 69, Academic Press.

Chu, Y. H., J. C. Li, T. Y. Jin, and H. H. Wang, 2009: Application of T/P altimeter backscatter data to land surface observation. J. Geodesy Geodyn., 29, 104-108. (in Chinese)

Cox, C. M. and B. F. Chao, 2002: Detection of a large-scale mass redistribution in the terrestrial system since 1998.
Science, 297, 831-833, doi: 10.1126/science.1072188. [Link]

Freeman, J. and P. A. M. Berry, 2006: A new approach to retracking ocean and coastal zone multi-mission altimetry. Proceeding of 15 Years of Progress in Radar Altimetry, Venice, Italy.

Fu, L. L. and A. Cazenave, 2001: Satellite Altimetry and Earth Sciences, A Handbook of Techniques and Applications, International Geophysics Series Volume 69, San Diego, Academic Press.

Guo, H. D., C. Wang, X. Y. Wang, and Y. S. Shi, 1997: ERS-1 WSC data for global land surface monitoring. J. Remote Sens., 1, 277-281. (in Chinese)

Guo, J., C. Hwang, X. Chang, and Y. Liu, 2006: Improved threshold retracker for satellite altimeter waveform retracking over coastal sea. Prog. Nat. Sci., 16, 732738.

Guo, J., X. Chang, Y. Gao, J. Sun, and C. Hwang, 2009: Lake level variations monitored with satellite altimetry waveform retracking. IEEE J. Sel. Top. Appl. Earth Obs. Remote Sens., 2, 80-86, doi: 10.1109/JSTARS. 2009.2021673. [Link]

Guo, J., Y. Gao, C. Hwang, and J. Sun, 2010: A multi-subwaveform parametric retracker of the radar satellite altimetric waveform and recovery of gravity anomalies over coastal oceans. Sci. China Earth Sci., 53, 610616, doi: 10.1007/s11430-009-0171-3. [Link]

Guo, J., J. Sun, X. Chang, S. Guo, and X. Liu, 2011: Correlation analysis of NINO3.4 SST and inland lake level variations monitored with satellite altimetry: Case studies of lakes Hongze, Khanka, La-ang, Ulungur, Issykkul and Baikal. Terr. Atmos. Ocean. Sci., 22, 203-213, doi: 10.3319/TAO.2010.09.17.01(TibXS). [Link]

Guo, J., L. Yang, X. Liu, C. Hwang, and H. Yang, 2012: On temporal-spatial distribution of backscatter coefficients over China determined by TOPEX/Poseidon mission. Sci. China Earth Sci., 55, 2068-2083, doi: 10.1007/s11430-012-4524-y. [Link]

Guzkowska, M. A. J., C. G. Rapley, W. Cudlip, and I. M. Mason, 1988: Satellite radar altimetry over arid regions. Proceedings of IGARSS' 88 Symposium, Edinburgh, Scotland, 13-16 September, Ref: ESA SP-284 (IEEE 88CH249-6).

Hwang, C., M. F. Peng, J. Ning, J. Luo, and C. H. Sui, 2005: Lake level variations in China from TOPEX/Poseidon altimetry: Data quality assessment and links to precipitation and ENSO. Geophys. J. Int., 161, 1-11, doi: 10.1111/j.1365-246X.2005.02518.x. [Link]

Hwang, C., J. Guo, X. Deng, H. Y. Hsu, and Y. Liu, 2006: Coastal gravity anomalies from retracked Geosat/GM altimetry: Improvement, limitation and the role of airborne gravity data. J. Geodesy, 80, 204-216, doi: 10. 1007/s00190-006-0052-x. [Link]

Lee, H., C. K. Shum, K. H. Tseng, J. Y. Guo, and C. Y. Kuo, 
2011: Present-day lake level variation from Envisat altimetry over the Northeastern Qinghai-Tibetan Plateau: Links with precipitation and temperature. Terr. Atmos. Ocean. Sci., 22, 169-175, doi: 10.3319/TAO. 2010.08.09.01(TibXS). [Link]

Papa, F., B. Legrésy, and F. Rémy, 2003: Use of the Topex/ Poseidon dual-frequency radar altimeter over land surfaces. Remote Sens. Environ., 87, 136-147, doi: 10. 1016/S0034-4257(03)00136-6. [Link]

Rapley, C. G., 1990: Satellite radar altimeters. In: Vaughan, R. A. (Ed.), Microwave Remote Sensing for Oceanographic and Marine Weather-Forecast Models, Kluwer
Academic, Dordrecht, The Netherlands, 406 pp.

Ridley, J., F. Strawbridge, R. Card, and H. Phillips, 1996: Radar backscatter characteristics of a desert surface. Remote Sens. Environ., 57, 63-78, doi: 10.1016/00344257(96)00018-1. [Link]

Seeber, G., 2003: Satellite Goedesy, $2^{\text {nd }}$ Edition, Berlin, Walter de Gruyter, 612 pp.

Skolnik, M., 1990: Radar Handbook, Boston, McGraw-Hill, 461-463.

Smith, W. H. F. and P. Wessel, 1990: Gridding with continuous curvature splines in tension. Geophysics, 55, 293-305, doi: 10.1190/1.1442837. [Link] 